\title{
Policy Termination: Causes, Resistance \& Its Implication to Policy Practices in Ethiopia
}

\author{
Dereje Terefe (PhD), Associate Professor in Social \& Public Policy \\ School of Policy Studies, ECSU, Addis Ababa, Ethiopia, March, 2019
}

\begin{abstract}
Policy termination received less scholarly attention than other policy processes such as policy formulation, adoption, implementation and evaluation that are in frequent discourse. The last function which completes the loop, termination, is only within our subconscious minds. Policy termination is a cessation of specific government's policies and programs. It implies that there is no need to continue with less outcomes and satisfactions from the clients. 'Sunset law' or legislative provision determines the longevity of a policy or program. The objective of this article is to examine the underlying causes of policy termination, its obstacles and implication to Ethiopian policy practices.
\end{abstract}

Key Terms: Public policy process, policy termination, and 'sunset' law.

DOI: $10.7176 / \mathrm{PPAR} / 9-5-03$

Publication date:May $31^{\text {st }} 2019$

\section{Introduction}

Policy termination has several dimensions. It may refer to policy redirection, program elimination, agency termination, fiscal retrenchments, etc. (Stewart, Hedge and Lester 2008). Scholars such as Brewer (1978) and Kaufman (1976) hold that policy termination became an area of study in the mid of 1970s upon scholars focus on the termination of organizations as a means of ending outworn or inadequate policies or programs. Discourse on policy termination, however, is overshadowed by the common and familiar policy processes such as policymaking, implementation and evaluation. Eugene Bardach (1976) characterizes such oversight as "underattended" subject.He further noted:

The reason for the scholarly neglect of this subject is that it is hard to study such an infrequent phenomenon as policy termination. One always suspects that each instance of the phenomenon is bound to be so idiosyncratic that no interesting generalizations will be possible. Since social science and social scientists thrive on generalizations rather than idiosyncrasies, termination has never become "hot" as a topic of academic interest (Bardach, p.123).

Traditionally, the common stages used to complete the loop and organizations and their managers rarely bother about policy termination. But termination is the difficult phase of the policy cycle. Once put in place, policies, programs, and agencies have a life of their own, as there is no incentive to admit past mistakes (Stewart, Hedge and Lester 2008). Conceptually, policy termination conveys the message that a policy that has been in place for sometimes is no more important or relevant than deciding to terminate it and replace it by a new one. Daniels (1997) further argues that policy termination is a "premeditated ending behavior, with the intent of a particular public organization or policy". To Bardach, "termination occurs, and when it occurs, it is either with a "big-bang" or a very "long whimper" (pp.123-131). This implies that policy termination is either concluded with unexpected discontents, or with long-term dissatisfactions that comes into final divorce.

It shows that in most cases, termination is not concluded in good terms, as far as its potential constituents are concerned. Nevertheless, termination presupposes the ultimate adjustment of people, policies, programs, systems and institutions that have ceased to work well. Brewer and deLeon (1983) and Hogwood and Peters (1982), further conceptualize termination as a phenomenon that "signals a beginning of the policy process as much as it does to its end". This implies that policies mature and grow over time; they also continue to address public problems but get surpassed in importance by new problems perceived to possess greater social importance and priority.

\section{Historical and theoretical perspectives of policy termination}

The ancient democracy of Athens had term limits for its representatives. Michael Harris (2001) argues that in their studies of classical democracies in Athens and elsewhere, English political thinkers in the seventeenth and eighteenth centuries learned the principles that justify limiting the time that a politician could hold office. Harris further noted that in the United States, the Articles of Confederation included term limits for representation in Section V, which stated that no person "should be capable of being a delegate for more than three years in any terms of six years (Petracca 1992). Consequently, it was learned that some great early Americans such as Franklin, Adams, and Jefferson supported office term limits.

The next question to grapple with is 'why institutions and policies terminate'? Policy termination theories are fundamentally about change - changes to the policy, and changes to the environment which, at one point in 
time, aided enactment. For instance, federal terminations are often linked to federal human power turnover, divided government, and other political shifts (e.g., Berry et al., 2010; Carpenter \& Lewis, 2004; Daniels, 1997; Lewis, 2002; Maltzman \& Shipan, 2008). Conversely, state and local terminations are less frequently and consistently connected to political forces (Graddy \& Ye 2008; Lowry 2005). In theory, states with rising unemployment and high corporate tax burdens are less likely to terminate incentives enacted to help create jobs, attract new industries, and reduce tax burdens. Though terminations could be interpreted as a signal of policy failure, they also provide political cover for policymakers who can more easily justify their changed position. They raise several questions and to many policy clientele, as termination for any reason looks like discrimination: "Why my policy? Why not that guy's policy?" If the case for termination is strong, however, political leaders of the constituency may accept the severance payment offered as the best deal (Behn 2018, 16).

Consequently, most attention that policy termination received has come from journalistic political expertise that severely criticizes government through campaign slogans against politicians alleging that the problem with government is government itself; and the solution is cutting government programs and making government smaller and less costly. Response to such calls, however, is not welcomed with an ease mood. It rather results in limited interest in cutting, reinventing, or terminating government programs when the deficit is gone, unemployment is down, inflation is stable (Daniels 2001,252). On the other hand, it's evident that any policy or organization that is not perceived by the public as addressing some of their important problems is considered as living on 'borrowed time'.

In the past, institutional or policy longevity has been counted as an important factor in the ability of an organization to survive and thereby avoid any thought of termination (deLeon1987; Kaufman 1980). Similarly, 'mature' organizations (those which remained serving long) are considered most immune to termination. Moreover, when an organization is considered invisible or complex, its ability to avoid termination is greater (Frantz 1992). This hints that organizations and policies that are obscure, or deal with a complex scientific program, appear a bit hard for the public to understand, and can deter or avoid any attempts of termination. Furthermore, constituents who used to benefit from a program often affect the ability of an organization to survive termination attempts (Shulsky 1976 Bardach 1976; deLeon 1983; Sapolsky 1976).

\section{Causes for policy failure and its eventual termination}

So far, we attempted to look into the conceptual, historical and theoretical perspectives of institutional or policy termination. It is generally believed that one of the causes for policy termination is its failure to address the problem it is intended to address. However, there are diverse views with regard to policy failure. To the view of Marianna Fotaki (2010), economists ascribe policy failures to the absence of incentive structures that could induce individuals to pursue their consistent and stable preferences (Friedman, 1982; Le Grand, 2003, 2006; Snower, 1993). Political scientists, on the other hand, identify the root-cause of policy failure with power of the entrenched interests of various political groups inside and outside government (Buchanan and Tullock, 1962; Coleman, 1990; Niskanen, 1971). Organizational theorists on their part draw on institutional conceptions of social life, defined as a set of shared meanings and practices established over lengthy periods to examine the causes for policy failure (March and Olsen, 1996; Powell and di Maggio, 1991).

What unites most of these varied accounts by policy analysts and organizational scholars is that policymaking, implementation, and their failures are assumed to be highly rational processes. While there are myriads of causes for policy failure and viewpoints, Signe (2017) has particularly focused on four major causes that can contribute to the issue under discussion. They include goal ambiguity, attitudes and discretion of front-line implementers, resource, politics and conflict. We will look at each of these essential variables in the subsequent paragraphs.

\section{a) Goal ambiguity}

Many policy scholars argue that the level of goal clarity or ambiguity matters a lot, when it comes to implementation success or failure (Matland 1995; Veronesi and Keasey 2015). Matland further holds that ambiguity falls into two main categories: ambiguity of goals and ambiguity of means. In the top-down policy models, goal clarity is an important independent variable that directly affects policy success, or otherwise. Goal ambiguity leads policy stakeholders to misunderstanding and uncertainty and therefore is often considered culpable in the implementation failure.

Furthermore, goal ambiguity affects bureaucratic behaviors and organizational performance (Chun and Rainey 2005). To the views of Matland (1995), in the implementation literature, especially those that adopt a top-down perspective, goal ambiguity has been traditionally considered a major cause of implementation failures; it creates uncertainty and misunderstanding. Overall, policy goal ambiguity not only results in differing implementation outcomes, but policy goals laid down in official documents will also face compromises and susceptible to multiple interpretations, where politics takes major toll in such instances.

\section{b) The role of front-line implementers}

One of the frequent challenges of implementation is the discords between the set goals and its implementation 
outcomes. To Winter (2011), what is known as "Principal-agent theory" offers a promising way for studying these relationships. The basic assumption is that a principal (manager) and his or her bureaucratic agents may not share all preferences from the other side of the scale, and the relationship is characterized by information asymmetry that systematically disadvantages principals (Winter 2011). In a similar vein, Zhan et al. (2014) highlight how lack of effective participation in the implementation of policies can pose problems.

Using China as a case in point, Zhan and associates examine what they define as "an inherent problem with a governance framework that combines centralized political authority with decentralized administration, in which central officials may have unchallenged authority but lack the institutional and organizational means to ensure that their decisions are fully implemented" (p. 1030). More specifically, lack of stakeholder participation in rule-making creates implementation difficulties (West 2005). In fact, this is what is not clear to most policymakers, as they tend to equate policy formulation and approval to direct or automatic implementation, two case scenarios that never match for valid reasons.

Most of the implementation deficits emerge from unnoticed challenges down the line. This concerns the issue of front-line implementers, known as "street-levelbureaucrats" (Lipsky 1980).The phrase, "street-level bureaucrats" may unwisely sound that they represent group of persons with 'little or no' professional competencies. However, the opposite is true; they are not "lay" persons as might have been thought. Rather, they are key policy stakeholders (e.g. teachers, social workers, police officers, health professionals, lawyers, and other practitioners, etc.), who by virtue of their profession, are there to implement policies at the point of contact with the target population (Lipsky 1971, 1980; Elmore 1979). They are public employees who directly interact with target group citizens and have substantial discretion in the execution of policy goals (Lipsky 1980; Tummers and Bekkers (2014). To Meyers and Nielsen (2012), street-level bureaucrats are persons who are the last link in the implementation chain (p. 305-18).

Put it succinctly, street-level bureaucrats are responsible for many of the centrally-cascaded policy decisions set for implementation. Hence, they exercise considerable discretions while implementing public policies (Meyers and Nielsen 2012). However, one important point that always passes unnoticed by policymakers and politicians is the fact that street-level bureaucrats are neither elected nor appointed by elected officials. As a result, they are relatively immune to electoral accountability. Moreover, neither elected officials nor the general citizens can exert full control over the street-level bureaucrats' day-to-day decisions, actions and impact on policy (Lipsky 1980; Sandfort 2000; Winter 2000); Meyers and Nielsen 2012, 316). Hence, it can be a good reminding and 'wake-up-call' for policymakers who assume that policymaking as an "end" in itself, leaving aside the role of such key implementers, street-level bureaucrats.

\section{c) Funding and Resources}

Though available funding and resources is not the only input and precondition for effective policy outcome or otherwise, it's believed that stable funding is considered instrumental to the successful policy implementation (Durlak and DuPre 2008, 336). Continuity and consistency of funding is preferred to a one-time grant (Greenhalgh et al. 2004, 608). To this end, Domitrovich et al. (2008) note that systemic interventions in any policy or program could take three to five years to achieve stated goals. This necessitates the continuity of resource flow to be made available for implementation to succeed. Finally, Peter deLeon (1983) examined numerous termination experiences that lacked financial resources to have led to policy failure and its eventual termination.

\section{d) Politics and Conflict}

Literature surrounding policy implementation suggests what counts as a problem and what counts as a solution, are heavily shaped by institutional history and stakeholder perspectives. The main principle in policy implementation is that implementation outcomes are decided by power, where one actor or a coalition of actors has sufficient power to force their will on other participants. Without doubt, such coercive and conflictual political situations pave the way for policy implementation failure. Governmental efficiency also influences policy termination where it becomes too costly in terms of service delivery.

However, at times, policies or programs can be terminated on the grounds of political ideology, without regard to financial imperatives. For instance, programs or policies that used to operate during the Cold War era should be terminated in the aftermath of the collapse of Communism. It also goes without saying that the harsh side of terrorist act will be relaxed, if not totally terminated in its entirety, with the blowing democratic winds nowadays in many developing countries.

Given the change and uncertainty that characterizes modern post-industrial societies, and given policymakers' limited ability to forecast the future, terminating policies that do not work due to the aforementioned variables is one way for policymakers to learn from their mistakes (Daniels 1994). Consequently, what is known as "Sunset Legislation", particularly in the developed world, presents a final reason for policy termination, requiring periodic review of state agencies that are under the threat of automatic termination unless recreated through laws such as sunset laws. We shall come back to what it means to 'Sunset Legislation', its brief historical upheaval and whether such laws are familiar to the Ethiopian long policy traditions. 


\section{Resistance to Policy Termination}

For a number of reasons, public policies or programs are found easy to terminate. Some scholars liken termination to embarking on a long and perhaps brutal political flight that will lead to hostile and very dedicated enemies (Behn 1977, 393). Behn further adds that termination is not a trial balloon, which is an important political instrument for testing what political winds will result in a new policy idea and how hard each will blow; generate public discussion, elicit views and arguments pro and cons, see supports and how it opposes the proposal, and how impassioned the two sides become.

In fact, a trial balloon may save a political leader from unnecessary embarrassment that comes from untested policy. However, termination balloon will produce no real test as the results are predestined. Those who benefit from the policy and those ideologically committed to it will start complaining immediately and loudly. They can also mobilize opposition and block the termination (Behn 1977). The following obstacles are given by termination scholars such as Zhang (2009), Daniels (2001), and DeLeon (1978) respectively.

\section{a) Intellectual reluctance}

It's generally taken for granted that people do not admit issues pertaining to their profession, livelihood, including their life. People do not consciously accept their death under normal circumstances. In the same vein, political leaders are reluctant to admit past mistakes. Persons who resist the end (termination) of a policy or program can be classified into three groups: policymakers (legislatives), policy executers, and policy beneficiaries (Zhang 2009). For policymakers, the admission of policy failure is tantamount to acknowledging mistakes in their career and this may significantly harm their fame as well as their future incentives: re-election.

For the executives, admitting policy failure whose outcome might lead to termination is critically avoided on the accounts of invested energy and labor in the process. Moreover, such harsh undertaking (termination) will also have detrimental response to their interest or development prospects. It may further result in considerable psychological and behavioral rejections in terms of salary, bonus, and other benefits. More than anything, the bureaucracy is afraid of losing its vested interests.

Cognitive resistance to realize policy shortcomings is reinforced by the underlying belief that policies are typically designed to solve, or at least reduce existing and future problems in the society. But we need to know that bureaucratic jobs such as policy legislation and governance depend on a program's continuation; when cut, it is assumed that "government positions with all of their benefits, prestige and stakes" will go with them. Hence, the simple 'face-saving' move against termination is the modest response by making marginal changes to programs or policies, and by claiming or projecting the cause for the failure to the cause of "no enough resources being spent on them" (Dye 2004, 325).

\section{b) Institutional Permanence}

There is a common tendency that almost all institutions want to maintain themselves for an indefinite period of time: to be'immortal' (Frantz 1992). As a result, organizations are made to perpetuate service to outlive a single sponsor or bureaucrat. In this way, the longer an institution exists, the more resilient it becomes (Downs 1967). Tendency for institutional permanence is, therefore, an assurance to political and bureaucratic life for an extended time, regardless of due efficiency and relevance desired.

The underlying insistence and quest for institutional permanence and attempts against policy termination is, primarily doing everything possible that endangers the survival of organizations. This is done by changing strategies, or adjusting the structure and finding ways to slow down and alleviate the pressure of policy termination, all of which give policy termination a negative picture (Biller 1976; deLeon 1978). Hence, there is no wonder that such hard battles have been and will be fought out against public policy termination, until the last drop of blood of institutions, leaders and groups.

\section{c) Anti-termination Coalition}

Public policies or programs have their own target groups. They develop coalitions of staff, constituents, and other interest groups who have common and deep interest to maintain them. DeLeon (1978) argues that the coalitions "may be strongly committed and intensely resist change and ignore" whatever comes contrary to the continuation of the policy or program to which they subscribe (Anderson 1984, 255). The target group will, therefore, form an anti-termination 'front' by mobilizing coalitions to successfully block the threatened plan for terminating a policy.

Whatever rationales and explanations are given, however, such institutions stand to deny failures as mere "allegations". In most of our public institutions, new stories produced by mainstream media, parliamentary assessments, or internal reports, if not consented, the fact always remains "unfounded" and only meant for blackening ("tilashetlemkebat") the 'fame' of the institution in charge. This situation can be demonstrated by a simple example. For instance, one can imagine the response that may erupt against a plan for reducing $5 \%$ of public employees' salary for environmental protection for two or three consecutive years. Similarly, if a government's fuel subsidy is lifted in a country that used meaningful subsidy for lower-income earners, one can see the coalition and havoc it might create.

In practical case, let's also consider that the Ethiopian government is currently subsidizing some selected 
food items and also covering urban employees' transport cost, and some level of condo-housing construction price, etc. One can imagine what would be the response from the respective target groups if such provisions are to wind up (terminate) by the end of 2011 E.C., at least in the shorter term. The moral of the story is that, whenever there is self-interest felt to have been threatened because of planned policy or program termination, the power of coalitions against the former unites and makes termination intractable (Zhang 2009). On the other hand, it should be noted that fear of such predicaments will not deter government's decision with the majority vote when policy or program termination is in favor of majority's interest. This measure employs what is known as 'sunset law' or legal provisions, which will be shortly discussed.

\section{d) Legal Obstacles}

Once public policies or programs are put in place with normative legislative procedures, it may be difficult to tamper withthe legitimacy, unless following the same legal procedures to terminate. According to deLeon (1978), constraints of "due process" of law can prohibitthe government from closing institutions along the policy they have been implementing for some time. Just like policy formulation, implementation and establishment of organizations follow certain legal procedures, so must policy termination and the withdrawal of organizations pursue. Such processes are not only time-consuming, but also complex.

\section{e) Start-up Costs}

One main clicking point on the part of policymakers is the cost of termination: the cost to be borne to start the new public policy or program to be in place. One can consider a critical public service being delivered for some time. For instance, if a government decides to terminate it on the grounds of its inefficient posturing in terms of critical resources, substituting alternate service, oreven compromising the quality for few months, is a matter of critical concern. In consequence, while deciding on terminating a policy, the externalities of the termination have to also be considered or calculated in many forms.

Furthermore, the 'moral repugnance' that the target groups feel that they are 'abandoned" is much more revealing and resonating in the negative than positive (Bardach 1976; Dye 2004; and Frantz 1992). We must note that, of all the costs, that of the political and social ones, are far-reaching. Governments are put in tight grips to make termination decisions due to high sunk cost and large amount of price already paid. In consequence, decision-makers are forced to persist with current policy by giving up the choice for termination, at least for some time to come.

Obstacles to terminate public policies or programs are not only the ones we have seen so far. Deeply entrenched interest groups, subscription to incrementalist model and dynamic conservatism, also play substantial roles not to go ahead for termination. Thomas R. Dye (2005) generalizes that concentrated benefits and dispersed costs, "logrolling" relations, between legislators and heads of public institutions, play significant inhibiting roles against policy termination.

The question is then, how can we fight with the indefinite 'permanence' of public policies, programs, and organizations while they behave with uncompassionate and inefficient service deliveries to the public? What have governments and institutions elsewhere learnt and devised to come out of inefficient and uncompassionate policies and institutions? It seems that innovation and innovativeness has helped them to withstand such challenges through what is known as "Sunset" laws or "Sunset" legislative provisions.

\section{Sunset laws (legislation) and termination}

According to Gray (1973) and Walker (1969), the history of sunset law or sunset provision goes back to circa 1960sUnited States of America. It was a legal provision for the automatic termination of government program, agency or law within or on a certain date unless the legislature acts to renew it in time. A definition by Jusitpedia (https://legal-dictionary.thefreedictionary.com/Sunset-laws) provides that sunset law is a law that states that a certain government program, benefit, agency, etc., will end on a certain date, and will go out of effect unless it is put back in place (https://www.britannica.com/topic/Sunset-law).

Such laws became common as both the federal and state governments grew steadily after 1950 in the United States of America. Consequently, many sunset laws were widely promoted in the 1970s as reform measures to eliminate bloated or unnecessarily swollen but unresponsive government policies and bureaucracies. The underlying need for sunset laws is that some government policies or programs sometimes cease to exist. For instance, as mentioned before, Cold War policies can stand as vivid examples.

Due to changing needs of governments, sunset laws help to make sure that public money is not being wasted for outdated policies or programs, and it also rescues governments from not going behind times with their rules and regulation. The law calls for periodic re-authorization requirements for laws to help government to make sure that certain policies, laws, agencies, etc. still need to continue exist and operate. In some countries, sunset advisory commissions are set, where government agencies undergo review every 10 or 12 years to go through the sunset legislation. Accordingly, government agencies are only entitled to exist for a given year and date after which they cannot be legal upon their expiration time or year.

To this end, all US states have adopted sunset legislation which would empower them terminate a policy or 
program after conducting an empirical analysis and evaluation (Common Cause 1977; Gray 1973; and Savage 1978). However, as we have discussed elsewhere in this paper, it's important to note that termination does not take place without taking prior measures, as every "termination signals the beginning of a policy process as much as it does its end (Brewer and deLeon 1983, 385). In other words, termination gives way to the rebirth and creation.

Sunset laws or legislations are not without opposition, however. There are divisions between policymakers as well as specific target groups whose interest is directly linked to the effects of termination. However, despite stiff confrontations between what are characterized as "reformers" and "guardians" (Cronbach 1980), many scholars believe that sunset laws have encouraged legislative oversight to keep public policies and programs more responsive to their constituents than otherwise. After sunset laws have become common, most policies or programs put in place had a specified period to operate after which they have two main options: renewal before the due date, or facing termination.

\section{Implication of policy termination and sunset laws to Ethiopia}

We have examined in the preceding parts that the sole objective of policy or program terminationis mainly to maintain policy responsiveness and thereby enhance government efficiency. We have also touched upon that both termination and innovation or renewal go hand-in-hand as public needs goes on sustainable and continuous basis. Termination without substitution (innovation) would lead to uncalled-for crises than the battling view to permanence between the reformers and the guardians. The question is, how is policy or institutional termination played out or implicated in Ethiopia?

Before looking at its implicative practice, it's important to admit that, in Ethiopia, policy as a concept and practice is a subject more spoken than understood or known. It can be said that issues regarding policy and policy responsiveness has been left to few institutions and segments of the society or experts. In consequence, attempts to policy analysis and evaluation is largely left to the economics elite to determine the economic rationality of a policy, a project or a program, as though public policy is devoid of political, social, cultural, historical, technological and environmental rationalities. Hence, it can be argued that whatever analysis is sought by politicians and policymakers, it is solely cost-benefit analysis (CBA) which feeds into policy (economic) efficiency, as opposed to policy effectiveness which is the cardinal goal to be achieved.

Indeed, one of the serious omissions in this area is the fact that most of our higher education institutions seem to shy away the subject, perhaps considering policy science as a 'taboo'. The probable cause might be the subject's arm's-length relations with politics. The overall predicament, however, is that the level of policy awareness, knowledge and skills of most policy actors in the country couldnot develop to the level desired. This gap may, to some extent, include members of the legislative body of the nation at federal and state levels. The federal parliament and regional state councils (supreme institutions) are considered first-level or major policystakeholders. They are the clearing-houses for all of the development policies of the nation.

A look at the situation of policy or program termination in Ethiopia can shed a different scenario had we have policy evaluation and termination stock-taking practice in each of the public institutions. Admittedly, however, there are no rich research outputs on the subject, and we lack officially documented policy termination reports on the basis of sunset laws or legislations. In consequence, there is lack of official policy effectiveness audit to know the magnitude of policy evaluation and its eventual termination and innovation. Though there is a need to take a case-by-case sectoral inventory as to how many public policies or programs have given way to new ones (innovation), the constant review of some sectors, such as urban land lease and investment policies, tax policies, justice reform policies, etc. to some extent, could be counted as termination and innovation cases in point.

These are, however, considered the tip of the ice berg in light of the excessive 'permanence' of some public institutions and policies decades after decades. It also seems that we don't have concrete termination devices where a stringent legislative oversight is applied to ensure accountability at each level in almost all of our development policies or programs. However, from what we used to live, there could be several public institutions and policies that 'out-lived' and kept burning our nerves year-on and year-off, both in terms of their quality service deliveries and overall efficiency and effectiveness at federal and state levels.

It can also be argued there could be dozens of institutions and policies that are awaiting sunset laws or legislations in the termination league in the country. In consequence, we cannot be sure whether the recent down-sizing and merger of the former 28 ministries and agencies to 20 can fall within the policy termination and innovation domains. If it is, it must get an historic record of its kind and the beginning of implementation of the sunset law. On the other hand, in the face of fast-advancing policy responsiveness and citizens' unprecedented quest for change, there will be no doubt that sun set law will become a normative policy operating principle in Ethiopia to influence policy relevance and resource efficiency.

Sunset laws will also serve as litmus paper of institutional efficiency and effectiveness and their survival for their subsequent service life-span. In response, legislatives at both federal and regional state levels, need to apply 
sunset law if they have to live up to their expectations (institutional oversight and scrutiny), as per the constitutional provisions and policy mandates given to them. The advancing quest for accountability will also serve as unprecedented leverage for policy transparency and the observance of rule of law in the same.

\section{Selected References}

Anderson, J. E. 1984, 2006. Public Policy Making: An Introduction; Houghton Mifflin: Boston

Bardach, E. (1976). "Policy termination as a political process," Policy Sciences 7:123 131.

Behn, R. D. (1980a). Symposium editor "Leadership in an era of retrenchment," Public Administration Review 40(6): 603604

Behn, R. D. (1980b). "Leadership for cut-back management: the use of corporate strategy," Public Administration Review 40(6): 613-620.

Behn, R. D. (1978). "How to terminate a public policy: a dozen hints for the would-be terminator," Policy Analysis 4(3): 373-413.

Bell, D. (1975). "The revolution of rising entitlements", Fortune 91:98 103.

Biller, R. P. (1980). "Leadership tactics for retrenchment," Public Administration Review 40(6): 604609.

Biller, R. P.(1976). "On tolerating policy and organizational termination: some design considerations," Policy Sciences 7: 133-149.

Brewer, G. D. (1978). "Termination: hard choices, harder questions," Public Administration Review 38(3): 338344.

Brewer, G. D. (1974). "The policy sciences emerge: to nurture and structure a discipline," Policy Sciences 5(2): 239- 244.

Brewer, G. D. and deLeon, P. (1983). The Foundation of Policy Analysis, Homewood, I11: Dorsey.

Cameron, J. M. (1978). "Ideology and policy termination: restructuring California's mental health system," in J. V. May and A. B. Wildavsky (eds.) The Policy Cycle, Beverly Hills: Sage, pp. 301-328

Common, Cause. 1977. Sunset: A Common Cause Proposal for Accountable Government. WD: Common Cause Cronbach, L. J. and Associates (1980). Toward Reform of Program Evaluation, San Francisco: Jossey- Bass.

Daniels, M. R. 2001. Program and Organizational Termination. International Journal of Public Administration. 24 (3), 249-262

1997. Terminating Public Programs. M.E. Sharpe: Armonk, NY, 1997.

1995, Organizational Termination and Policy Continuation: Closing the Oklahoma Public Training Schools. Policy Sciences. 28 (2, June), 301-316.

DeLeon, P. 1983. "Policy evaluation and program termination," Policy Studies Review 2(4): 631-647.

1978. "Public policy termination: an end and a beginning," Policy Analysis 4(3): 369-392.

Dereje Terefe. 2016. Policy mandates and practices in a federal system: The case of Oromia National Regional State (Caffee). Lambert Academic publishing

2015. Assessment of Wereda Policy Implementation Capacity: Opportunities and Challenges (The case of selected Wereda Administrations in Yeka Sub-city, Addis Ababa

2012. Policy Practice and challenges in Ethiopia. Lambert Academic Publishing Company

2016. The Extent of public opinion to endorse or halt public policies: A Review of recent change of policy goal posts in Ethiopia. Public Policy and Administration Research, Vol. 6, No.10, 2016

Dereje Terefe and Tiruye Alemu. 2018. Assessment of the causes for policy-Implementation dichotomy Narratives in Ethiopia: The case of selected public institutions. Public Policy and Administration Research, Vol.8, No.10, 2018

Dery, David. 1984. Evaluation and Termination in the Policy Cycle. Political Sciences, 17 (13-26).

Frantz, J. 1992. Reviving and Revising a Termination Model. Pol. Sci. 175. 10.

Geva-May, I. (2004). Riding the wave of opportunity: Termination in public policy. Journal of Public Administration Research and Theory, 14, 309-333

Gray, Virginia. 1973. Innovation in the States: A Diffusion Study. American Political Sci. Review 50: 49-57

Harris, Michael. 2001. Policy Termination. The case of term limits in Michigan. International Journal of Public Administration. 24(30, 323, 339

Harris,M. 1997. Policy Termination: Uncovering the Ideological Dimension .IJPA 1997, 20, 2151-2175.

Jeffrey L. Pressman, J.L. and Aaron Wildavsky B.1973 Implementation. Berkeley and Los Angeles: Los Angeles: University of California Press.

Kaufman, H. 1980. Time, Chance and Organizations: Natural Selection in a Perilous Environment; Chatham House: Chatham, NJ.

Kaufman, H. 1976. Are Government Organizations Immortal? Brookings Institution: Washington, DC,

Kirkpatrick, S. E., Lester, J. P., \& Peterson, M. R. (1999). The policy termination process: A conceptual framework and application to revenue sharing. Review of Policy Research, 16, 209-238.

Lambright, W .H. 1976. Sapolsky, H.M. Terminating Federal Research and Development Programs. Pol. Sci. 7 
(2, June), 199-213.

Lasswell, H. D. (1971). A Pre- View of Policy Sciences, New York: American Elsevier

Lewis, D. E. (2002). The politics of agency termination: Confronting the myth of agency immortality. Journal of Politics, 64, 89-107.

Maltzman, F., \& Shipan, C. R. (2008). Change, continuity, and the evolution of the law. American Journal of Political Science, 52, 252-267.

Petracca, M.R.1992. Rotation in Office: The History of an Idea. In Limiting Legislative Terms; Benjamin, G., Malbin, M.J., Eds.; Congressional Quarterly Press: Washington, DC.

Savage, R. L. 1978. Policy Innovativeness: A Trait of American States. Journal of Politics 40: 212-224

Shulsky, A.N. 1976. Abolishing the District of Columbia Motorcycle Squad. Pol. Sci. 7 (2, June), 183-197

Thom, Michael. 2017. Fade to Black? Exploring Policy Enactment and Termination Through the Rise and Fall of State Tax Incentives for the Motion Picture Industry. American Politics Research. Vol. 45 (1) 85-108.

Turnhout, Esther. 2009. The rise and fall of a policy: policy success and the attempted termination of ecological corridors policy in the Netherlands. Policy Sci., 42: 57-72..

Zhang, Lizhen. 2009. Study on Obstacles to Policy Termination. Journal of Politics and Law. Vol. 2, NO 4 